\title{
Detecção de estruturas parasitárias em hortaliças comercializadas na cidade de Florianópolis, SC, Brasil
}

\author{
Bolivar Soares, Geny Aparecida Cantos*
}

${ }^{1}$ Departamento de Análises Clínicas (ACL), Universidade Federal de Santa Catarina - UFSC

*Correspondência:

G. A. Cantos

Departamento de Análises Clínicas,

Universidade Federal de Santa

Catarina (UFSC) - Trindade

88090-100 - Florianópolis, SC, Brasil

Email: geny@ccs.ufsc.br
Analisou-se a presença de formas transmissiveis de enteroparasitas em hortaliças consumidas cruas na cidade de Florianópolis, SC, no periodo de junho de 2003 a maio de 2004. Foram estudadas amostras alface (Lactuca sativa), agrião (Nasturtium officinale) $e$ rúcula (Chicarium $\mathrm{sp),} \mathrm{num} \mathrm{total} \mathrm{de} 750$, provenientes do comércio ("sacolões", supermercados e feiras livres). Tais amostras foram lavadas e submetidas ao método de sedimentação espontânea em água por 24 horas. Todas as variedades de hortaliças examinadas apresentaram elevados percentuais de contaminação, porém com maior freqüência no agrião. Observou-se uma grande variedade de protozoários, responsáveis pela transmissão elevada de enfermidades intestinais, na população da região metropolitana de Florianópolis. Ressalta-se a importância das hortaliças na transmissão de enfermidades intestinais, havendo conseqüentemente necessidade de medidas que propiciem uma melhoria na qualidade higiênico-sanitária destas.

\section{INTRODUÇÃO}

As hortaliças, especialmente as consumidas cruas, têm especial importância para a saúde pública, pois são amplamente consumidas pela população, e podem conter cistos de protozoários, ovos e larvas de helmintos, servindo como uma importante via de transmissão de parasitas intestinais (Simões et al., 2001).

A principal forma de contaminação por enteroparasitas em hortaliças dá-se, principalmente, no uso de água contaminada por material fecal de origem humana, utilizada na irrigação de hortas. Outras formas seriam a contaminação do solo por uso de adubo orgânico com dejetos fecais, o contato das hortaliças com ani- mais como aves, moscas e ratos, e também a forma inadequada como as hortaliças são manuseadas e transportadas (Robertson, Gjerde, 2001).

Em Florianópolis, recentemente, foi verificado um elevado grau de parasitismo em indivíduos que atuavam em uma empresa de alimentos, em feiras livres e "sacolões" (Nolla, Cantos, 2005). Em relação às hortaliças, apesar da relevância do tema, são poucas as informações sobre a qualidade desses alimentos assim comercializados (Feranadez et al., 2002),

Assim, este trabalho considerou a possibilidade de monitorar, por meio da pesquisa de enteroparasitas, a contaminação fecal ambiental, em hortaliças comercializadas em alguns pontos de venda da cidade de Florianópolis, 
fornecendo dados de interesse para a Saúde Pública e a Vigilância Sanitária sobre o estado higiênico desses produtos.

\section{MATERIAL E MÉTODOS}

\section{Colheita de amostras}

Foram colhidas, entre os meses de junho de 2003 a maio de 2004, 750 amostras entre as espécies alface (Lactuca sativa) de variedade crespa, rúcula (Chicarium $s p$ ) e agrião (Nasturtium officinale), em cinco pontos de comercialização diferentes da cidade de Florianópolis: dois estabelecimentos denominados "sacolões", dois supermercados e uma feira livre.

Para a obtenção e transporte do material ao laboratório foram utilizados sacos plásticos estéreis (devidamente fechados e etiquetados) e fichas de registro para anotações da procedência, espécie de verdura, data, entre outros. Como unidade amostral aleatória, foi estabelecido, para as alfaces, o pé (ou touceira), independentemente do peso ou tamanho que apresentaram; enquanto que, para o agrião e a rúcula considerou-se o maço, constituído de folhas agrupadas e seguras por um laço.

\section{Análise das hortaliças}

As hortaliças produzidas e adquiridas nos referidos postos de comercialização foram encaminhadas para o Laboratório de Estágio do Departamento de Análises Clínicas, da Universidade Federal de Santa Catarina. O tempo decorrido entre a coleta das amostras e o início do exame foi em média aproximadamente de duas horas e meia.

As hortaliças foram desfolhadas, fatiadas e homogeneizadas, e $100 \mathrm{~g}$ de cada uma delas foram lavadas com $200 \mathrm{~mL}$ de uma solução detergente $(0,3 \mathrm{mg} / \mathrm{mL}$ de lauril éter sulfato de sódio e $0,25 \mathrm{mg} /$ $\mathrm{mL}$ de álcool láurico etoxilado). O produto da lavagem foi filtrado em gaze para um frasco cônico e deixado em repouso por 24 horas. Em seguida, 5,0 mL do sedimento foram retirados e centrifugados a $1.500 \mathrm{rpm}$, durante dois minutos, desprezando-se o sobrenadante e ajustando-se o volume final deste para $0,5 \mathrm{~mL}$ com água destilada. Após a homogeneização do sedimento, retirou-se $0,05 \mathrm{~mL}$ deste para uma lâmina de vidro, coberta com lamínula, utilizando como corante o lugol, para o exame direto em um microscópio óptico. A leitura foi realizada em triplicata, sendo calculado o número total de cistos, ovos e larvas (NT), de acordo com Oliveira e Germano (1992).

\section{Análise estatística}

Foi aplicado o teste de duas proporções $\left(\mathrm{x}^{2}\right)$ para verificar se houve diferenças significativas entre os percentuais de contaminação parasitológico encontrados nas hortaliças. Para a análise das médias totais de cistos de protozoários, ovos e larvas de helmintos (NT), foi aplicado o teste de Tukey e suas freqüências relativas em diferentes hortaliças. O teste $t$ foi aplicado para verificar se havia diferenças significativas, considerando o NT entre os seguintes estabelecimentos: "sacolão" e "sacolão", supermercado e supermercado, "sacolões" e supermercados, "sacolões" e feira livre, supermercado e feira livre. O teste $t$ também foi aplicado para analisar as diferenças encontradas nas freqüências entre helmintos e protozoários. Em todos os testes aplicados, somente os valores de $p<0,05$ foram considerados estatisticamente significativos. Para indicar a precisão dessas estimativas, foi calculado o intervalo de confiança (IC) de $95 \%$.

\section{RESULTADOS E DISCUSSÃO}

O Brasil, como um país tropical em desenvolvimento, possui clima e situação socioeconômica favoráveis à ocorrência de doenças parasitárias.Em países em desenvolvimento, tanto em áreas rurais quanto em urbanas, devido às baixas condições sanitárias, as parasitoses intestinais são amplamente disseminadas, e as hortaliças servem como um dos principais veículos de transmissão de enfermidades intestinais (Mesquita et al., 1999). Estes alimentos, em especial os consumidos em saladas cruas, podem conter larvas e ovos de helmintos e cistos de protozoários, provenientes de águas contaminadas por dejetos fecais de animais e/ou homem (Coelho et al., 2001).

Neste trabalho, as variedades de hortaliças examinadas foram a alface, o agrião e a rúcula, que são as mais consumidas pela população. A figura 1 mostra que o agrião foi a hortaliça mais parasitada $(70,4 \%)$, seguido das alfaces $(60 \%)$ e por último a rúcula $(56 \%)$. A análise freqüêncial indicou diferenças estaticamente significativas entre a alface e o agrião e entre a rúcula e o agrião (teste $\mathrm{X}^{2}$ ). A aplicação do teste de Tukey para as médias totais dos valores NT mostrou que as colunas seguidas de letras iguais não diferiram entre si de forma significativa (tabela I).

É possível que a estrutura do vegetal interfira com o grau de contaminação deste, pois o agrião, apresentando folhas múltiplas e separadas, com grande área de contato, permitiria maior adesão de determinados 
enteroparasitas. A alface apresenta folhas largas, firmemente justapostas, o que dificulta a aderência dos cistos de protozoários, ovos e larvas de helminto. Outra hipótese é que muitos ovos de helmintos podem sobreviver por períodos de tempo mais prolongados no meio, o que poderia justificar as freqüências superiores encontradas no agrião, cujo cultivo exige terrenos permanentemente úmidos (Oliveira, Germano, 1992). É possível ainda que o maior parasitismo encontrado no agrião deve-se em parte pela forma como este é adubado. De fato, informações obtidas junto aos agricultores que forneciam hortaliças para os "sacolões" e supermercados mostraram que o agrião sofria, uma vez por semana, o processo chamado "chuva de adubo", que é a utilização de estrume de gado dissolvidos na água de irrigação. Isto pode explicar por que os valores obtidos no agrião mostraram-se significantemente maiores do que os encontrados nas outras hortaliças.

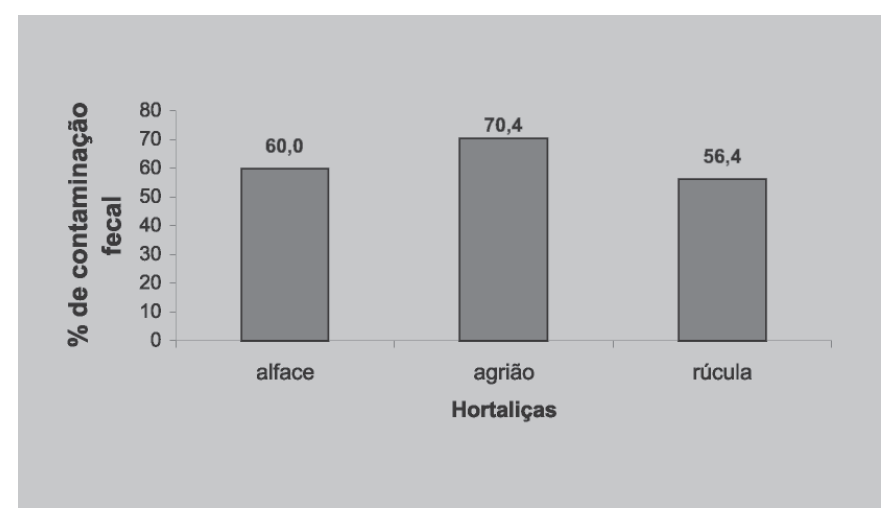

FIGURA 1 - Porcentagem de unidades contaminadas por enteroparasitas em função do tipo de hortaliça.
Na tabela I pode-se notar também que, nas 750 amostras analisadas, o percentual de contaminação por cistos de protozoários, ovos e larvas de helmintos variou de $38 \%$ a $82 \%$ de contaminação; percentuais considerados elevados, quando comparados a outros trabalhos como de o Silva et al. (1995), no Rio de Janeiro (21,4\%), e o de Guilherme et al. (1999), em Maringá PR (16,6\%). A maior taxa registrada em nosso trabalho poderia ser por conseqüência das más condições de transporte e acondicionamento das hortaliças, das baixas condições higiênico-sanitárias dos que manipulam alimentos, da água de irrigação, e talvez de outras condições de cultivo.

Notou-se, por exemplo, que a maioria dos produtores que forneciam hortaliças para os "sacolões" não usavam luvas durante a coleta, nem todas as verduras eram embaladas em sacos plásticos, o transporte destas, na sua maioria, era feito em caminhão aberto, e as propriedades rurais desses produtores, em grande parte, não possuíam alvará da prefeitura.

De fato, as hortaliças oriundas dos "sacolões" $1 \mathrm{e}$ 2 foram mais contaminadas que as dos supermercados e feira-livre; embora considerando o NT, a diferença foi somente significativa entre "sacolões" e feira livre $(p=0,0454)$ (Tabela II). Levando em conta as freqüências de parasitas encontradas nas hortaliças, houve diferenças significativas entre "sacolões" e feira livre $(p<0,001) \mathrm{e}$ entre supermercado e feira livre $(p=0,432)$.

O maior parasitismo encontrado nas hortaliças dos "sacolões" pode ser atribuído a vários fatores. Um deles poderia ser a água de irrigação utilizada pelos produtores que forneciam hortaliças para os "sacolões". Essa água é obtida do rio Rachadel, en-

TABELA I - Resultado das análises parasitológicas de 750 hortaliças (das espécies alface, agrião e rúcula), comercializadas na cidade de Florianópolis, no período de junho de 2003 a maio de 2004

\begin{tabular}{lcccccc}
\hline $\begin{array}{l}\text { Pontos de } \\
\text { comercialização }\end{array}$ & \multicolumn{2}{c}{ Alface*N (\%) NT } & \multicolumn{2}{c}{ Agrião*N (\%) NT } & \multicolumn{2}{c}{ Rúcula*N (\% ) NT } \\
\hline "Sacolão” 1 & $37(74)$ & 4.250 & $40(80)$ & 7.679 & $33(66)$ & 2.740 \\
"Sacolão” 2 & $38(76)$ & 2.630 & $41(82)$ & 5.980 & $35(70)$ & 1.350 \\
Supermercado 1 & $30(60)$ & 3.370 & $37(74)$ & 5.390 & $25(50)$ & 1.130 \\
Supermercado 2 & $26(52)$ & 870 & $38(76)$ & 4.510 & $27(54)$ & 900 \\
Feira livre & $19(38)$ & 440 & $20(40)$ & 440 & $21(42)$ & 980 \\
Total & $150(60)$ & $11.560^{\mathrm{b}}$ & $176(70,4)$ & $23.990^{\mathrm{b}}$ & $141(56,4)$ & $7.100^{\mathrm{a}}$ \\
& & $(294 ; 4.329)^{* *}$ & & $(1.451 ; 8.144)^{* *}$ & & $(900 ; 2.740)^{* *}$ \\
\hline
\end{tabular}

*(corresponde a 250 unidades examinadas); $\mathrm{N}$ e\% representam, respectivamente, o número e percentual de hortaliças contaminadas; NT (número total de cistos de protozoários, ovos e larvas de helmintos por $100 \mathrm{~g}$ de amostra); ${ }^{\mathrm{a}, \mathrm{b}} \mathrm{Tukey}$ $(\mathrm{p}<0,05),{ }^{* *}$ intervalo de confiança superior e inferior (IC 95\%). 
quanto a água utilizada pelos produtores que forneciam hortaliças para os supermercados era proveniente de córregos naturais. Já os agricultores da feira livre foram os únicos que não possuíam na propriedade sistema de irrigação, sendo esta feita manualmente. É possível que as águas de córregos naturais recebam menos esgoto domiciliar e, conseqüentemente, suas águas estejam menos contaminadas.

Os menores percentuais de contaminação, observados nas amostras oriundas da feira livre, podem ser atribuídos, entre outros fatores, às suas melhores condições de cultivo, pois estas hortaliças recebem cuidados mais adequados por parte dos horticultores, que, por exemplo, no processo de cultivo, usavam como adubo apenas o esterco de galinha e não o agrotóxico. Já os produtores que forneciam hortaliças para os supermercados e "sacolóes" usavam alternativamente esterco de galinha e esterco de boi e agrotóxico. Essa hipótese reflete o fato de que foram encontrados ovos de Trichostrongylus spp, um parasita de ruminantes e pouco comum em humanos, somente em hortaliças oriundas de supermercados e "sacolões". Assim, é necessário que os serviços de extensão rural orientem os agricultores para manejarem adequadamente o estrume, focalizando os cuidados domésticos no preparo e consumo dos alimentos.

Com relação às variações entre as freqüências específicas dos protozoários (tabela III), pode-se notar que Entamoeba spp. tiveram freqüencias mais expressivas (76\%), seguido de Blastocystis hominis $(20,8 \%)$, Endolimax nana (14,\%) e Giardia spp. (12,4\%). Uma pesquisa realizada com manipuladores de alimentos, na cidade de Florianópolis, mostrou que estes mesmos protozoários estavam presentes naquela população, o que sugere que esses indivíduos desempenhavam um papel importante na transmissão de doenças veiculadas por alimentos (Nolla, Cantos , 2005).Este trabalho reforça, pois, esta hipótese.
A tabela III mostra que houve uma maior contaminação parasitária de cistos de protozoários do que por ovos e larvas de helmintos; diferença extremamente significativa $(p<0.010)$. É possível atribuir esse elevado percentual de protozoários em hortaliças com base no trabalho com manipuladores de alimentos, realizado por Nolla e Cantos (2005), em Florianópolis, onde os autores verificaram uma prevalência significativa de protozooses em relação às helmintoses. Embora os riscos de contaminação dependam de muitas variáveis, os autores sugerem que a população esteja realizando uma automedicação para helmintos, o que deve contribuir também para a compreensão das variáveis desta pesquisa.

Por outro lado, é preciso considerar que a variação no tipo e freqüência de enteroparasitas registrados neste trabalho deve-se em parte à localidade e à metodologia utilizada. Foi dado ênfase aos níveis de contaminação, de forma que não foi utilizado um método específico para identificação de parasitas como os coccídeos. Assim, a freqüência desses e/ou outros parasitas pode estar sendo substimada. No entanto, independente de suas freqüências, os parasitas encontrados nas hortaliças comercializadas na Grande Florianópolis não diferiram substancialmente de outros descritos na literatura (Guimarães et.al., 2003).

Neste estudo houve uma ocorrência expressiva de ovos de Toxocara sp nas amostras de rúculas (5,2\%). A ocorrência dos ovos deste parasita nas hortaliças está diretamente ligada à presença de cães ou gatos parasitados. De fato, esses animais domésticos foram observados junto a todos fornecedores das hortaliças comercializadas em Florianópolis.

Com relação às variações entre as freqüências específicas dos demais helmintos, este efeito parece ter sido discreto. Apesar de os ovos de Ascaris lumbricoides apresentarem uma grande resistência no solo, suas prevalências nos inquéritos parasitológicos no Sul do país têm se mostrado relativamente baixas.

TABELA II - Análise estatística e médias do número total de cistos de protozoários, ovos e larvas de helmintos por 100 g de amostra nas 750 amostras analisadas, (das espécies alface, agrião e rúcula), oriundas de diferentes estabelecimentos, no período de junho de 2003 a maio de 2004

\begin{tabular}{lcc}
\hline Pontos de comercialização & Médias (IC95\%) & Valor de $p$ (teste $t)$ \\
\hline "Sacolões" & $5.220(1.650-12.146)$ & $0,4780^{\mathrm{a}} ; 0,2671^{\mathrm{b}} ; 0,0454^{\mathrm{c}}$ \\
Supermercados & $3.038(1.075-7.152)$ & $0,5237^{\mathrm{b}} ; 0,5237^{\mathrm{d}}$ \\
Feira livre & $620(154-1.394,5)$ & \\
\hline
\end{tabular}

IC( intervalo de confiança); ${ }^{a}$ (entre os dois sacolões); ${ }^{\text {( }}$ (sacolões e supermercados); ${ }^{\mathrm{c}}$ (sacolões e feira livre; ${ }^{\mathrm{d}}$ (entre os dois supermercados); e (supermercados e feira livre). 
TABELA III - Distribuição de protozoários e helmintos em 750 hortaliças (das espécies alface, agrião e rúcula) examinadas em Florianópolis, no período de maio de 2003 a junho 2004

\begin{tabular}{|c|c|c|c|c|c|c|}
\hline \multirow[t]{2}{*}{ PROTOZOÁRIOS } & \multicolumn{2}{|c|}{ Alface $(\mathrm{N}=250)$} & \multicolumn{2}{|c|}{ Agrião $(\mathrm{N}=250)$} & \multicolumn{2}{|c|}{ Rúcula(N=250) } \\
\hline & $\mathrm{F}$ & $\%$ & $\mathrm{~F}$ & $\%$ & $\mathrm{~F}$ & $\%$ \\
\hline Entamoeba spp. & 190 & 76,0 & 236 & 94,4 & 186 & 74,4 \\
\hline Blastocystis hominis & 52 & 20,8 & 62 & 24,8 & 32 & 12,8 \\
\hline Endolimax nana & 35 & 14,0 & 32 & 12,8 & 41 & 16,4 \\
\hline Giardia spp. & 31 & 12,4 & 23 & 9,2 & 30 & 12,0 \\
\hline Médias/IC 95\% & $\begin{array}{c}77,00^{\mathrm{a}} \\
(43,7 ; 197,9)\end{array}$ & & $\begin{array}{r}88,2 \\
(43,7 ; 1\end{array}$ & & $\begin{array}{r}72,2 \\
(48,7 ; 19\end{array}$ & \\
\hline \multicolumn{7}{|l|}{ HELMINTOS } \\
\hline Ancilostomídeos & 22 & 8,8 & 56 & 22,4 & 18 & 7,2 \\
\hline Strongyloides spp. & 12 & 4,8 & 13 & 5,2 & 06 & 2,4 \\
\hline Trichostrongylus spp. & 11 & 4,4 & 18 & 7,2 & 08 & 3,2 \\
\hline Toxocara canis & $02 *$ & 0,8 & 06 & 2,4 & 13 & 5,2 \\
\hline Ascaris lumbricoides & 04 & 1,6 & 16 & 6,4 & 00 & 0,0 \\
\hline Hymenolepis nana & 02 & 0,8 & 02 & 0,8 & 00 & 0,0 \\
\hline Enterobius vermicularis & 01 & 0,4 & 00 & 0,0 & 00 & 0,0 \\
\hline Trichiuris trichiura & 00 & 0,0 & 01 & 0,4 & 00 & 0,0 \\
\hline Médias/IC 95\% & $\begin{array}{c}7,71^{\mathrm{b}} \\
(0,55 ; 145)\end{array}$ & & $\begin{array}{r}16,00 \\
(1,44 ; 3\end{array}$ & & $\begin{array}{r}8,00 \\
(0,11 ; 1\end{array}$ & \\
\hline
\end{tabular}

Onde $\mathrm{F} \mathrm{e} \%$ representam a freqüência e percentagem de hortaliças parasitadas em relação à distribuição de ovos, larvas de helmintos e cistos de protozoários; ${ }^{\mathrm{a} e \mathrm{~b}}(\mathrm{p}<0,01)$, IC(intervalo de confiança inferiores e superiores).

Em Itajaí, a ocorrência foi de 3,8\% (Blatt, Cantos, 2003); e, em Florianópolis, com manipuladores de alimentos, este percentual foi de $1,65 \%$ (Nolla, Cantos, 2005). Considerando que este parasita é estenoxeno do homem, provavelmente os resultados registrados nesta pesquisa sejam também o reflexo dessa parasitose em humanos.

Contudo, é de salientar que as fontes de contaminação das hortaliças são amplas, incluindo diversos vetores como insetos e roedores, o tipo de água e adubos utilizados, o meio de transporte das hortaliças e também manipuladores de alimentos (Coelho et al., 2001; Carvalho et al., 2003). A boa higiene é medida protetora fundamental contra doenças de origem alimentar, e o indivíduo que fornece, prepara e serve o alimento deve construir barreiras sanitárias entre este e seus consumidores, de forma que as pessoas que os manipulem sejam selecionadas e tenham conhecimentos e atitudes para operação de um sistema de preparação de alimentos. O desenvolvimento de postura crítica como consumidor também é fundamental para atingir a produção de alimentos seguros, e depende fundamentalmente de investimentos em educação.

Conclui-se que as verduras comercializadas nos pontos de venda analisados na cidade de Florianópolis têm destaque na transmissão das enteroparasitoses, havendo necessidade de medidas profiláticas no sentido de melhorar a qualidade higiênica destas.

\section{ABSTRACT \\ Detection of parasitic structures in vegetables commercialized in the city of Florianópolis, SC, Brazil}

The presence of transmissible forms of enteroparasites in vegetables consumed raw in Florianópolis city was evaluated in the period concerned between June 2003 and May 2004. A total of 750 samples, including lettuce (Lactuva sativa), watercress (Nasturtium officinale) and of rocket (Chicarium $\mathrm{sp})$, commercially available from street markets and supermarkets, were analyzed. All samples were washed and submitted to the sedimentation method. Elevated degrees of contamination were found in all samples analyzed, with higher frequencies being found in the watercress samples. A large variety of protozoans were detected, the levels of which are compatible with the elevated 
frequency of occurrence in the population of the metropolitan region of the city of Florianópolis. Therefore, the importance of the vegetables in the transmission of intestinal diseases is emphasized, which requires adequate measurements to be taken in order to provide an improvement in the hygienicsanitary quality of the vegetables.

UNITERMS: Vegetables. Intestinal parasites. Contamination offood.

\section{REFERÊNCIAS BIBLIOGRÁFICAS}

BLATT, J.M.; CANTOS, G.A. Evaluation of techniques for diagnosis of Strongyloides stercoralis in human immunodeficiency virus (HIV) positive and HIV negative individuals in the city of Itajaí, Brazil. Bras. $J$. Infect. Dis., v.7, p. 402-408, 2003.

CARVALHO, J.B.; NASCIMENTO, E.R.; NETO, J.F.N.; CARVALHO, I.S.; CARVALHO, L.S.; CARVALHO J.S. Presença de helmintos em hortaliças fertilizadas com lodo de lagoa de estabilização. Rev. Bras. Anal. Clin Rev., v.35, n. 2, p. 101-103, 2003.

COELHO, L.P.S.; OLIVEIRA, S.M.; MILMAN, M.H.A. Detecção de formas transmissíveis de enteroparasitas na água e nas hortaliças consumidas em comunidades escolares de Sorocaba, São Paulo, Brasil. Rev. Soc. Bras. Med. Trop., v.34, n.5, p. 479-482, 2001.

FERANADEZ, A.A.; MARTINEZ, H.E.P.; PEREIRA, P.R.G.; FONSECA, M.C.M. Produtividade, acúmulo de nitrato e estado nutricional de cultivos de alface, em hidropônia, em função de fontes de nutrientes. Hortic. Bras., v.2, n.2, p:195-200, 2002.

GUILHERME, A.L.F.; ARAÚJO, S.M.; FALAVIGNA, D.L.M.; PUPULIM A.R.; DIAS, M.L.; OLIVEIRA, H.S. Prevalência de enteroparasitas em horticultures e hortaliças da Feira de Maringá, Paraná. Rev. Soc. Bras. Med. Trop., v.32, n. 4, p.405-411, 1999.
GUIMARÃES, A.M.; ALVES E.G.L.; FIGUEIREDO, H.C.P; COSTA, G.M; RODRIGUES, L.S. Freqüência de enteroparasitas em amostras de alface (Lactuca sativa) comercializadas em Lavras, Minas Gerais. Rev. Soc. Bras. Med. Trop., v.36, n. 5, p.621-623, 2003.

MESQUITA, V.C.C.; SERRA, C.M.B.; BASTOS, O.M.P.; UCHÔA, C.M.A. Contaminação por enteroparasitas em hortaliças comercializadas nas cidades de Niterói e Rio de Janeiro, Brasil. Rev. Soc. Bras. Med. Trop., v.34, n.4, p.189-194, 1999.

NOLLA, A.C.; CANTOS, G.A. Relação entre ocorrência de enteroparasitoses em manipuladores de alimentos e aspectos epidemiológicos em Florianópolis-SC. Cad. Saúde Pública, v. 21, p.109-118, 2005.

OLIVEIRA, C.A.F.; GERMANO, P.M.L. Estudo da ocorrência de enteroparasitas em hortaliças comercializadas na região metropolitana de São PauloSP, Brasil. I- Pesquisa de helmintos. Rev. Saúde Pública, v.26, n.4, p. 283-289, 1992.

ROBERTSON, L.J.; GJERDE, B. Ocurrence of parasites on fruits and vegetables in Norway. J. Food Protection, v.64, p.1793-1798, 2001.

SILVA, J.P.; MARZOCHI, M.C.A.; CAMILO-COURA, L. Estudo da contaminação por enteroparasitas em hortaliças comercializadas nos supermercados da cidade do Rio de Janeiro. Rev. Soc. Bras. Med. Trop., v.28, n.3, p. 237-341, 1995.

SIMÕES, M.; PISANI, B.; MARQUES, E.G.L.; PRANDI, M.A.G.; MARTINI, M.H.; CHIARINI, P.F. Hygienicsanitary conditions of vegetables and irrigation water from kitchen gardens in the municipality of Campinas, SP. Braz. J. Microb., v.32, n.4, p. 331-333, 2001.

Recebido para publicação em 21 de dezembro de 2005. Aceito para publicação em 04 de agosto de 2006. 